\title{
Multipurpose Internet Mail Extensions
}

National Cancer Institute

\section{Source}

National Cancer Institute. Multipurpose Internet Mail Extensions. NCI Thesaurus. Code C74930.

A standard file format for transferring non-textual data over the internet. 